\title{
EVALUATING THE EFFICACY OF URETEROSCOPIC MANAGEMENT OF UPPER URETERIC CALCULI USING STONE CONE ENTRAPMENT DEVICE- A PROSPECTIVE, RANDOMISED, CONTROLLED STUDY
}

\author{
Sivasankar Govindaraju1, Arulkumar Ettappan ${ }^{2}$ \\ 1 Professor, Department of Urology, Government Royapettah Hospital, Royapettah, Chennai, Tamilnadu, India. \\ ${ }^{2}$ Postgraduate Student, Department of Urology, Kilpauk Medical College/ Government Royapettah Hospital, Royapettah, Chennai, \\ Tamilnadu, India.
}

\section{ABSTRACT}

\section{BACKGROUND}

Endoscopic management of ureteral stones with new improved techniques have resulted in greater stone-free rates with low morbidity. However, problems remain preventing to achieve a $100 \%$ stone free rate with endoscopic management. One such problem is retrograde migration of proximal ureteric calculus during ureteroscopic lithotripsy. There are many retropulsion devices and manoeuvres available and practiced nowadays.

In this study, we aim to assess the efficacy of stone cone in the ureteroscopic management of upper ureteric calculi.

\section{MATERIALS AND METHODS}

This is a prospective, randomised, controlled study conducted in the Department of Urology in Government Kilpauk Medical College Hospital, Kilpauk and Government Royapettah Hospital, Chennai during the period February 2016 - August 2017.80 patients with proximal ureteric calculus who presented to our department were included in this study. Our patients were randomised into 2 groups with 40 patients in each group. In Group 1, ureteroscopic pneumatic lithotripsy of proximal ureteric calculus with the help of stone cone was done and in Group 2 lithotripsy was done without stone cone. Stone clearance rates were compared between the two groups and results were analysed.

\section{RESULTS}

80 patients with proximal ureteric stones were randomly distributed into 2 groups. Group 1 included 40 patients who underwent ureteroscopic pneumatic lithotripsy with stone cone. The success rate in terms of complete stone clearance is $95 \%$ (38 out of 40 ) patients in the immediate postoperative period. Residual fragments up to $5 \mathrm{~mm}$ was noted in 2 cases. In Group 2 with 40 patients who underwent standard ureteroscopic pneumatic lithotripsy without stone cone were included. The stone clearance rate in this group is $70 \%$ (28 out of 40 patients) in the immediate postoperative period. 8 patients had stone migration into renal pelvis and 4 patients had residual fragments of more than $5 \mathrm{~mm}$. Follow-up after 1 month by KUB or spiral CT scan showed complete clearance of the stone in all 40 patients in the Stone Cone group. In Group 2, complete clearance of the stone occurred in 37 patients. Proximal stone migration was prevented in all patients in the Stone Cone group with $100 \%$ success rate versus without stone group (8 patients had stone migration into the kidney) with success rate of $80 \%$. Success rate in terms of preventing stone migration showed Stone Cone group superior with a statistically significant difference $(\mathrm{p}<0.05)$. Similarly, the stone-free rate in the Stone Cone group was $100 \%(40 / 40)$ versus $87.5 \%$ (35/40) in the other group in the one-month follow-up period.

\section{CONCLUSION}

Our study demonstrated superior proximal stone clearance rates when ureteroscopic lithotripsy was done with stone cone. It is also safe and efficient in preventing proximal stone migration. Hence, it can be considered in managing upper ureteric calculus as an effective retropulsion device.

\section{KEY WORDS}

Proximal Ureteric Calculi, Stone Cone, Ureteroscopy, Retropulsion Device, Lithotripsy.

HOW TO CITE THIS ARTICLE: Govindaraju S, Ettappan A. Evaluating the efficacy of ureteroscopic management of upper ureteric calculi using stone cone entrapment device- a prospective, randomised, controlled study. J. Evolution Med. Dent. Sci. 2018;7(25): 2921-2925, DOI: $10.14260 /$ jemds/2018/658

\section{BACKGROUND}

Proximal fragment migration during ureteroscopic lithotripsy is a common problem occurring in 5 to $40 \%$ of cases.[1] The migrating stone fragments may necessitate additional

'Financial or Other Competing Interest': None.

Submission 30-04-2018, Peer Review 01-06-2018,

Acceptance 08-06-2018, Published 18-06-2018.

Corresponding Author:

Dr. Arulkumar Ettappan,

Postgraduate Student,

Department of Urology,

Kilpauk Medical College, Hospital,

Kilpauk, Chennai, Tamilnadu, India.

E-mail: k.arul21@yahoo.in

DOI: $10.14260 /$ jemds $/ 2018 / 658$ (c) $(1)$ procedures involving ureterorenoscopy with further fragmentation or extraction with retrieval devices, ureteral stenting[2] or secondary procedures such as shock wave lithotripsy and ureteroscopy. In addition, residual stone fragments may serve as a source of recurrent stone growth, persistent infection and renal colic. The risk of upward migration is influenced by the pressure of the irrigant fluid, type of energy source used for intracorporeal lithotripsy, the site and degree of calculus impaction and the degree of proximal ureteral dilation. Smaller stones and greater proximal ureteral dilation or hydroureteronephrosis increase the rate of stone migration. $[1,3,4]$

Various strategies have been employed to prevent retrograde migration of stone fragments during ureterolithotripsy. Procedural modifications such as placing 
the patient in the reverse Trendelenburg position and decreasing the irrigant pressure and flow rate have been tried. Different stone-trapping devices have been created specifically to prevent retrograde stone migration and assist with fragment extraction. $[5,6]$

The Stone Cone is a device that aims to prevent proximal calculus migration and enable safe extraction of small calculi during ureteroscopic lithotripsy. In addition to these uses, it can be a substitute for ureteral guidewire, thus maintaining continuous ureteral access. $[7,8,9,10]$ In this study, we evaluated the efficacy of stone cone device during intracorporeal lithotripsy of upper ureteral calculi.

\section{Aim of the Study}

To assess the efficacy of Stone Cone device in preventing retrograde calculus migration and stone clearance in the ureteroscopic management of proximal ureteric calculus.

\section{MATERIALS AND METHODS}

This is a prospective, randomised, controlled study conducted in the Department of Urology in Government Kilpauk Medical College Hospital, Kilpauk and Government Royapettah Hospital, Chennai during the period February 2017 - January 2018. 80 patients with proximal ureteric calculus who presented to our department were included in this study. Sample size was calculated according to our convenience. Our patients were randomised into 2 groups with 40 patients in each group using computer generated random numbers table. In Group 1, Ureteroscopic pneumatic lithotripsy of proximal ureteric calculus with the help of stone cone was done and in Group 2 lithotripsy was done without stone cone. Stone clearance rates were compared between the two groups and results were analysed.

Patients between 20 to 50 years of age with a single proximal ureteric calculus ranging between 8 to $20 \mathrm{~mm}$, who have consented for the study were included in this study. Patients with bleeding disorders, significant medical comorbidities precluding surgery or anaesthesia, pregnancy, previous history of calculus disease on same side, ipsilateral endoscopic or open ureteric surgeries, any degree of ureteral stricture distal to the stone, stone impaction, clinical evidence of sepsis, coexistence of a renal calculus that were excluded from the study were excluded from this study. All patients were preoperatively thoroughly evaluated, and the location of the stone was confirmed by non-contrast computed urography (CT). All patients underwent ureteroscopy under general or regional anaesthesia using 8.5 Fr semi-rigid (Storz) ureteroscope.

In Group 1, Stone Cone using $3 \mathrm{Fr}$ with a coil size of $10 \mathrm{~mm}$ was inserted cystoscopically under fluoroscopic guidance for ureteral occlusion to bypass the stone. After the tip of the carrying catheter was passed above the stone into the proximal ureter, the device was then activated and pulled back to fit over the stone. The device was used only as a backstop, not to extract the fragments. Then URS and fragmentation of the stone using pneumatic lithotripsy were performed. When the stone was fragmented, the device was pulled under vision to extract the fragments. A double J stent was inserted over the guidewire.

The rate of retrograde stone migration during ureteroscopic lithotripsy procedures and the stone-free rate using the Stone Cone device versus without stone cone device were the primary and the secondary study outcome, respectively. The procedure was considered successful in either group if no proximal stone migration occurred, if the stone was fragmented completely (approximately $2-3 \mathrm{~mm}$ particles), and if the calculus subsequently was seen to be cleared on follow-up radiographs. Postoperative KUB was performed the next morning (24 hours after the procedure). Patients were discharged and returned back after 1 month from the procedure for follow-up KUB or spiral CT scan and for removal of the double-J stent.

Follow-up of the patients was performed with x-ray film of the urinary tract (KUB) after 24 hours to exclude stone migration and assess the clearance of stones. Another was performed after 1 week. All cases of migration were treated with adjunctive extracorporeal shock wave lithotripsy (ESWL). The main outcome we analysed in this study is the stone clearance rate in either groups.

Results on categorical measurements are presented in percentage. Chi-square test has been used to find the significance of study parameters on categorical scale between two groups. Student ' $t$ ' test has been used to determine the significance between two group means. All analyses were two tailed and $\mathrm{p}<0.05$ was considered significant. SPSS version 16.0 was used for data analysis.

\section{RESULTS}

80 patients with proximal ureteric stones were randomly distributed into 2 groups. Group 1 included 40 patients who underwent ureteroscopic pneumatic lithotripsy with Stone Cone. The success rate in terms of complete stone clearance is 95\% (38 out of 40) patients in the immediate postoperative period. There were no cases of stone migration. Residual fragments up to $5 \mathrm{~mm}$ was noted in 2 cases and medical expulsion therapy was given for these patients. No significant complications were noted in this study group. Operative time was 30 to 55 minutes with a mean operative time of 45.85 mins. The average hospital stay in this group was $44.4 \mathrm{hrs}$. All patients were discharged without any complications.

In Group 2 with 40 patients who underwent standard ureteroscopic pneumatic lithotripsy without stone cone were included. The stone clearance rate in this group is $70 \%$ (28 out of 40 patients) in the immediate postoperative period. 8 patients had stone migration into renal pelvis and 4 patients had residual fragments more than $5 \mathrm{~mm}$. Haematuria occurred in 4 cases, which cleared few days post operatively. Other than that, no significant complications were noted in this group too. The operative time was 30 to 40 minutes with average of 36.9 minutes. The average hospital stay was 67.8 hours in this group.

\begin{tabular}{|c|c|c|}
\hline Operative Time & Mean (in Mins) & Standard Deviation \\
\hline Group 1 & 45.85 & 7.97930 \\
\hline Group 2 & 36.9 & 3.55037 \\
\hline P value $<0.0001$ (Statistically significantly lower in Group 2) \\
\hline \multicolumn{3}{|c|}{ Table 1 } \\
\hline
\end{tabular}

The mean operative time compared between two groups showed Group 2 had statistically significant lesser operative time compared to Group 1 with p-value $<0.0001$. It has been observed in our study that patients undergoing lithotripsy with stone cone required more operative time due to the time taken for the application of the device. 


\begin{tabular}{|c|c|c|}
\hline Hospital Stay & Mean (in Hours) & Standard Deviation \\
\hline Group 1 & 44.4 & 7.78163 \\
\hline Group 2 & 67.8 & 9.23538 \\
\hline p-value < 0.0001 (statistically significantly lower in Group 1) \\
\hline \multicolumn{3}{|c|}{ Table 2 } \\
\hline
\end{tabular}

When comparing the average hospital stay between the two groups, Group 1 patients had a significantly lesser hospital stay with mean of $44.4 \mathrm{hrs}$. than Group 2 with mean of $67.8 \mathrm{hrs}$.

\begin{tabular}{|c|c|c|}
\hline $\begin{array}{c}\text { Immediate } \\
\text { Postoperative Period }\end{array}$ & $\begin{array}{c}\text { Stone Cone } \\
\text { Group }\end{array}$ & $\begin{array}{c}\text { Non-Stone Cone } \\
\text { Group }\end{array}$ \\
\hline $\begin{array}{c}\text { Number of stone } \\
\text { migrations }\end{array}$ & 0 & 8 \\
\hline $\begin{array}{c}\text { Complete stone } \\
\text { clearance }\end{array}$ & $38(95 \%)$ & $28(70 \%)$ \\
\hline $\begin{array}{c}\text { Significant residual } \\
\text { fragments }\end{array}$ & 0 & 2 \\
\hline $\begin{array}{c}\text { Clinically insignificant } \\
\text { residual fragments }\end{array}$ & 2 & 2 \\
\hline \multicolumn{2}{|c|}{ Table 3 } \\
\hline
\end{tabular}

Follow-up after 1 month by KUB or spiral CT scan showed complete clearance of the stone in all 40 patients in the Stone Cone group. In Group 2, complete clearance of the stone occurred in 37 patients. 8 patients with stone migration were subjected for ESWL and 7 achieved stone clearance and one patient had clinically significant residual fragment. Whereas out of the 4 patients with residual fragments, 2 patients had a clinically significant residual fragment requiring intervention and 2 patients had clinically insignificant residual fragments.

\begin{tabular}{|c|c|c|}
\hline $\begin{array}{c}\text { Follow-Up after 1 } \\
\text { Month }\end{array}$ & $\begin{array}{c}\text { Stone Cone } \\
\text { Group }\end{array}$ & $\begin{array}{c}\text { Non-Stone Cone } \\
\text { Group }\end{array}$ \\
\hline $\begin{array}{c}\text { Complete stone } \\
\text { clearance }\end{array}$ & $40(100 \%)$ & $35(87.5 \%)$ \\
\hline $\begin{array}{c}\text { Significant residual } \\
\text { fragments }\end{array}$ & 0 & 3 \\
\hline $\begin{array}{c}\text { Clinically insignificant } \\
\text { residual fragments }\end{array}$ & 2 & 2 \\
\hline \multicolumn{2}{|c|}{ Table 4 } \\
\hline
\end{tabular}

\begin{tabular}{|c|c|c|c|}
\hline $\begin{array}{c}\text { Success Rate } \\
\text { (Complete Stone } \\
\text { Clearance) }\end{array}$ & Group 1 & Group 1 & P value \\
\hline $\begin{array}{c}\text { Immediate } \\
\text { postoperative period }\end{array}$ & $95 \%$ & $70 \%$ & $\mathrm{P}=0.0035$ \\
\hline After 1 month & $100 \%$ & $87.5 \%$ & $\mathrm{P}=0.0219$ \\
\hline \multicolumn{3}{|c|}{ Table 5 } \\
\hline
\end{tabular}

When compared between two groups in terms of complete stone clearance rate, Group 1 patients who underwent ureteroscopic lithotripsy with stone cone showed statistically significant clearance rate when compared with Group 2 patients.

\section{DISCUSSION}

Treatment of ureteral stones with URS is the most common modality used and is more practical and tolerable. It has also showed higher success rates and invariably became the standard care of treatment in managing ureteral stones in combination with various auxiliary procedures.

Initially, distal and mid-ureteric stones were managed successfully with URS. With the advances in endoscopic technology, the proximally located ureteric stones can also be nowadays managed successfully with URS. Several studies have shown that ureteroscopic pneumatic lithotripsy has a stone clearance rate of upto $85 \%$. It is also cost effective and well tolerated by most of the patients.

The use of Stone Cone with URS in our study increased the success rate up to $95 \%$ and prevents stone migration with no significant complications. The results of our studies were similar to various previous studies conducted with stone cone. Stone cone is a device developed to prevent migration of upper ureteric calculi during ureteroscopic lithotripsy. It is very efficient in preventing stone migration and helps in safe removal of calculus.[11,12,10]

Pneumatic and electrohydraulic lithotrites cause more retrograde propulsion of the ureteral stones than holmium: YAG laser and ultrasonic lithotrites.[13,14,15,16] Proximal stone migration is more likely with smaller stones and greater proximal ureteral dilation or hydronephrosis. Retrograde stone migration results in a longer operating time, more invasive endoscopy and an increase in residual stones and the need for secondary procedures, leading to higher morbidity and greater expense.[17] To prevent stone migration, surgeons have traditionally used a number of manoeuvres including reverse Trendelenburg position to optimise the effects of gravity and decreased irrigation pressure and flow rate. These techniques, however, compromise surgeon comfort and visibility and can therefore also prolong procedures.[18,19]

In centres such as ours that primarily use pneumatic lithotripters and have limited access to flexible ureteroscopes, antiretropulsion devices are critical to the success of the operation. Numerous devices have been employed to reduce the incidence of proximal stone migration during ureteroscopy including the use of ureteral baskets, Lithocatch, Lithovac, ${ }^{[19]}$ passport balloon, parachute, entrapment net ( $\mathrm{N}$ Trap), Accordion, BackStop and the Stone Cone.[11,12,20]

The entrapment net (N Trap) is a relatively new ureteral occlusion device that is considered to be a reliable efficient mean for prevention of stone migration. It has a safety release to help prevent larger stones from being trapped within the basket. An in vitro report suggested equal efficacy with both Accordion and the Stone Cone, but there are no sufficient reports discussing its safety and efficacy [Ahmed et al 2009; Holley et al 2005].[21,22]

The Escape nitinol retrieval basket is a $1.9 \mathrm{Fr}$, zero-tip, four-wire stone retrieval basket. The benefit of the Escape basket over the Stone Cone and N Trap is the use of the device through the working channel of the ureteroscope [Vejdani et al 2009].

BackStop is a water-soluble biocompatible polymer with reverse thermosensitive properties. It exists as a liquid at temperatures below $16^{\circ} \mathrm{C}$ and as a soft but injectable gel at room temperature, and then transitions to a viscous gel at body temperature. BackStop is dispensed above the stone and forms a gel plug that conforms to the ureter and prevents the stone (s) from migrating up the ureter and potentially into the kidney. On completion of stone fragmentation and extraction, 
BackStop is dissolved by conventional saline irrigation [Rane et al, 2010b].[23,24]

The Stone Cone showed ease of placement, safety and efficacy for preventing retrograde stone migration without apparent ureteral damage. In our study the Stone Cone device prevented proximal stone migration in all patients, giving a $100 \%$ success rate. The Stone Cone was easily deployed, and all stones were fragmented into small particles without proximal migration.

Similarly, Desai and colleagues used the Stone Cone in 50 consecutive cases of upper and lower ureteral calculi with $100 \%$ success and no need for auxiliary procedures [Desai et al 2009].[7] Also, Maislos and colleagues used the device with $100 \%$ success in 19 consecutive patients with upper ureteral stones and concluded that it reduced morbidity and saved time and money [Maislos et al 2004].[12]

In a prospective, comparative study of 56 patients, Paradalidis and colleagues achieved a significantly higher stone-free rate using the Stone Cone compared with a flat wire basket. They also concluded that the Stone Cone was safe and effective [Paradalidis et al, 2005].[10]

Ali and colleagues proposed a new method to prevent retrograde displacement of ureteral stones during lithotripsy using lidocaine jelly [Ali et al, 2004].[25] They passed a 6 Fr ureteral stent beyond the stone through an $8 \mathrm{Fr}$ ureteroscope and instilled 1 to $2 \mathrm{~mL}$ of lubricating jelly before applying kinetic energy. They treated seven patients with this method. In all seven patients, stone displacement was prevented, and fragmentation was satisfactorily performed. They suggested that lubricating jelly instillation proximal to the ureteral stone during lithotripsy is an effective method of preventing retrograde stone displacement.

In our study, we compared the success rate of treating proximal ureteric calculi with and without stone cone device. The two groups of patients were comparable with regard to most of the preoperative parameters with no significant difference. Proximal stone migration was prevented in all patients in the Stone Cone group with $100 \%$ success rate versus without stone group ( 8 patients had stone migration into the kidney) with success rate of $80 \%$. Success rate in terms of preventing stone migration showed Stone Cone group superior with a statistically significant difference $(\mathrm{p}<0.05)$. Similarly, the stone-free rate in the Stone Cone group was $100 \%$ (40/40) versus $87.5 \%$ (35/40) in the other group in the one-month follow-up period.

The differences between the groups were in stone migration rate and stone-free rate. This difference was in favour of the Stone Cone group, which showed no proximal stone migration and higher stone-free rate and these differences were significant. This gives a privilege to the Stone Cone, which is preferred as an efficient device for prevention of stone migration.

\section{CONCLUSION}

The Stone Cone is safe and efficient in preventing proximal stone migration during ureteroscopic pneumatic lithotripsy. It maintained continuous ureteral access and demonstrated a statistically significant advantage in terms of proximal stone migration and stone-free rate and the need for auxiliary procedures. We recommend the ureteroscopic management of proximal ureteric calculi using Stone Cone and pneumatic lithotripsy.

\section{REFERENCES}

[1] Johnson DB, Pearle MS. Complications of ureteroscopy. Urol Clin North Am 2004;31(1):157-71.

[2] Chew BH, Knudsen BE, Denstedt JD. The use of stents in contemporary urology. Curr Opin Urol 2004;14(2):111-5.

[3] Hollenbeck BK, Schuster TG, Faerber GJ, et al. Comparison of the outcomes of ureteroscopy for ureteral calculi located above and below the pelvic brim. Urology 2001;58(3):351-6.

[4] Chow GK, Blute ML, Patterson DE, et al. Ureteroscopy: update on current practice and long term complications. J Urol 2001;165(2):71.

[5] Preminger GM, Tiselius HG, Assimos DG, et al. 2007 guideline for the management of ureteral calculi. J Urol 2007;178(6):2418-34.

[6] Dretler SP. Ureteroscopy for proximal ureteral calculi: prevention of stone migration. J Endourol 2000;14(7):565-7.

[7] Desai MR, Patel SB, Desai MM, et al. The Dretler stone cone: a device to prevent ureteral stone migration - the initial clinical experience. J Urol 2002;167(5):1985-8.

[8] Denstedt JD, Clayman RV. Electrohydraulic lithotripsy of renal and ureteral calculi. J Urol 1990;143(1):13-7.

[9] Willscher MK, Conway JF Jr, Babayan RK, et al. Safety and efficacy of electrohydraulic lithotripsy by ureteroscopy. J Urol 1988;140(5):957-8.

[10] Pardalidis NP, Papatsoris AG, Kosmaoglou EV. Prevention of retrograde calculus migration with the Stone Cone. Urol Res 2005;33(1):61-4.

[11] Dretler SP. The stone cone: a new generation of basketry. J Urol 2001;165(5):1593-6.

[12] Maislos SD, Volpe M, Albert PS, et al. Efficacy of the stone cone for treatment of proximal ureteral stones. J Endourol 2004;18(9):862-4.

[13] Küpeli B, Biri H, Isen K, et al. Treatment of ureteral stones: comparison of extracorporeal shock wave lithotripsy and endourologic alternatives. Eur Urol 1998;34(6):474-9.

[14] Kelly JD, Keane PF, Johnston SR, et al. Laser lithotripsy for ureteric calculi: results in 250 patients. Ulster Med J 1995;64(2):126-30.

[15] Boline GB, Belis JA. Outpatient fragmentation of ureteral calculi with mini ureteroscopes and laser lithotripsy. J Endourol 1994;8(5):341-3.

[16] Knispel HH, Klän R, Heicappell R, et al. Pneumatic lithotripsy applied through deflected working channel of miniureteroscope: results in 143 patients. J Endourol 1998;12(6):513-5.

[17] Delvecchio FC, Preminger GM. Management of residual stones. Urol Clin N Am 2000;27(2):347-54.

[18] Robert M, Bennani A, Guiter J, et al. Treatment of 150 ureteral calculi with the Lithoclast. Eur Urol 1994;26(3):212-5.

[19] Delvecchio FC, Kuo RL, Preminger GM. Clinical efficacy of combined Lithoclast and Lithovac stone removal during ureteroscopy. J Urol 2000;164(1):40-2. 
[20] Farahat YA, Elbahnasy AE, Elashry OM. A randomized prospective controlled study for assessment of different ureteral occlusion devices in prevention of stone migration during pneumatic lithotripsy. Urology 2011;77(1):30-5.

[21] Ahmed M, Pedro RN, Kieley S, et al. Systematic evaluation of ureteral occlusion devices: insertion, deployment, stone migration and extraction. Urology 2009;73(5):976-80.

[22] Holley PG, Sharma SK, Perry KT, et al. Assessment of novel ureteral occlusion device and comparison with Stone Cone in prevention of stone fragment migration during lithotripsy. J Endourol 2005;19(2):200-3.
[23] Rane A, Sur R, Chew B. Retropulsion during intracorporeal lithotripsy: What's out there to help? BJU Int 2010a;106(5):591-2.

[24] Rane A, Bradoo A, Rao P, et al. The use of a novel reverse thermo sensitive polymer to prevent ureteral stone retropulsion during intracorporeal lithotripsy: a randomized, controlled trial. J Urol 2010b;183(4):1417-21.

[25] Ali AA, Ali ZA, Halstead JC, et al. A novel method to prevent retrograde displacement of ureteric calculi during intracorporeal lithotripsy. BJU Int 2004;94(3):441-2. 